\title{
ECONOMIAS EXTRATIVAS E DESENVOLVIMENTO: CONTRADIÇÕES E DESAFIOS
}

Bruno Milanez ${ }^{2} 3$

Universidade Federal de Juiz de Fora

Resumo: Argumenta-se que, apesar dos estudos críticos realizados ao longo do século XX sobre os riscos de um crescimento baseado em recursos naturais, a emergência do neoliberalismo, a crescente financeirização do setor das commodities e a ascensão da Ásia impulsionaram o aprofundamento da dependência do extrativismo em países latino-americanos. Essa dinâmica resultou em novos e complexos conflitos territoriais e inviabilizou a capacidade de reprodução de muitas comunidades tradicionais. Esse processo explicitou limitações das críticas até então formuladas, levando à construção de novos paradigmas que buscavam complementar parte das análises existentes e tensionar as propostas de solução que essas análises apresentavam. Ao longo do texto, com base em uma extensa revisão bibliográfica, primeiramente se descrevem as principais abordagens sobre a relação entre extrativismo e crescimento econômico do século XX: Economia Neoclássica, Estruturalismo e Teoria da Dependência, Trocas Ecológicas Desiguais, Maldição dos Recursos Naturais e Redes Globais de Produção. Em seguida, apresenta-se o contexto econômico e político da região entre os anos 2000 e 2020 e abordam-se exemplos de políticas públicas voltadas para o fortalecimento do extrativismo. Por fim, discute-se a natureza territorial dos conflitos resultantes e avalia-se como eles levaram a novas proposições para se debaterem as relações entre ambiente, sociedade e economia.

Palavras-chave: mineração, desenvolvimento, neoextrativismo, pós-extrativismo, pós-desenvolvimento.

\section{EXTRACTIVE ECONOMIES AND DEVELOPMENT: INCONSISTENCIES AND CHALLENGES}

Abstract: Along with the text, I argue that, despite the critical studies developed in the XXth century about the risks of a natural-resourcebased economic growth, the emergence of neoliberalism, the increasing financialisation of the commodity sector and the rise of Asia increased the dependence of Latin American countries on extractivism. This dynamic produced new and complex territorial conflicts and destroyed the reproductive capacity of many traditional communities. This process made explicit the limitation of the existing economic critiques, resulting in the proposal of new paradigms, which complemented prevailing analysis and questioned their proposed solutions. Based on an extensive literature review, I first describe the main approaches that debated the relationship between extractivism and economic growth: Neoclassic Economics, Structuralism and Dependency Theory, Unequal Ecological Exchange, the Resource Curse, and the Global Production Networks. Then, I describe the regional socio-political context between 2000 and 2020, and present some public policies developed to strengthen extractivism in Latin America. Finally, I debate the nature of the resulting territorial conflicts and evaluate to what extent they proposed new perspectives to discuss the relationship between the environment, society and economy.

Keywords: mining, development, neoextractivism, post-extractivism, post-development

\section{ECONOMÍAS EXTRACTIVAS Y DESARROLLO: CONTRADICCIONES Y DESAFÍOS}

Resumen: Diferentes estudios críticos, realizados a lo largo del siglo XX, señalaron los riesgos del crecimiento económico basado en los recursos naturales. Sin embargo, todavía se argumenta que el surgimiento del neoliberalismo, la creciente financiarización de los sectores económicos vinculados a los commodities y la expansión acelerada en Asia han profundizado la dependencia del extractivismo en los

1. Doutor em Política Ambiental, professor associado, Programa de Pós-graduação em Geografia da Universidade Federal de Juiz de Fora. Orcid: https://orcid.org/0000-0002-5330-7407. E-mail: bruno.milanez@ufjf.edu.br.

2. O autor gostaria de agradecer a Ana Saggioro Garcia pelo debate inicial que deu origem a este texto, bem como a Beatriz Macchione Saes, Tadzio Peters Coelho, Rodrigo Salles Pereira dos Santos e Luiz Jardim Wanderley pela leitura cuidadosa e pelas sugestões a versões preliminares deste artigo.

3. O autor gostaria de agradecer à Fundação de Amparo à Pesquisa do Estado do Rio de Janeiro (FAPERJ) pelo apoio para a publicação deste artigo (Processo E-26/010.002189/2019). 
países latinoamericanos. El agravamiento del extractivismo provocó nuevos y complejos conflictos territoriales e hizo inviable la reproducción social de muchas comunidades tradicionales. Este nuevo contexto explicitó las limitaciones de las críticas al proyecto de desarrollo en curso, conduciendo a la construcción de nuevos paradigmas que buscaban complementar parte de los análisis existentes y cuestionar las propuestas para superarlo. Primero, a partir de una extensa revisión de la literatura, sistematizamos los principales enfoques de la relación entre el extractivismo y el crecimiento económico del siglo XX: Economía Neoclásica, Estructuralismo y Teoría de la Dependencia, Intercambio Ecológicamente Desigual, Maldición de los Recursos y Redes Globales de Producción.Posteriormente, abordamos el contexto económico y político, así como políticas públicas orientadas a fortalecer el neoextractivismo en América del Sur, entre los años 2000 y 2020. Al final, discutimos el carácter territorial de los conflictos derivados del extractivismo y evaluamos cómo estos llevaron a nuevas propuestas políticas y teóricas para debatir las relaciones entre naturaleza, sociedad y economía.

Palabras clave: minería, desarrollo, neoextractivismo, postextractivismo, posdesarrollo.

O papel da mineração no crescimento econômico dos países tem sido alvo de um longo debate. De um lado, com origem em uma perspectiva normativa baseada no pensamento econômico clássico do século XIX, o setor foi apresentado como capaz de contribuir positivamente para as economias nacionais. Por outro lado, estudos empíricos e analíticos desenvolvidos ao longo do século XX apresentaram uma série de questionamentos dessa proposição e explicitaram os limites e desafios de se garantir o crescimento econômico de longo prazo das nações com base na extração dos recursos minerais. Mais recentemente, trabalhos mudaram o foco das economias nacionais e do comércio internacional para se debruçar sobre aspectos territoriais e conflitos em escala subnacional envolvendo grupos sociais específicos. Tais pesquisas explicitaram novas dimensões dos impactos negativos criadas por tal modelo de crescimento (GRAULAU, 2008).

Este texto tem como objetivos descrever as principais teorias econômicas que se propuseram a debater a relação entre extrativismo e desenvolvimento; analisar até que ponto elas foram insuficientes para evitar um aprofundamento do modelo extrativista na América Latina e refletir sobre como isso impulsionou novos pensamentos que viriam a questionar o próprio conceito de desenvolvimento.

Dessa forma, argumento que, apesar dos alertas feitos desde os anos 1950 sobre os riscos de um crescimento baseado em recursos naturais, a emergência do neoliberalismo a partir dos anos 1970, bem como a crescente financeirização do setor de commodities e a ascensão econômica da Ásia no início dos anos 2000 impulsionaram o aprofundamento da dependência do extrativismo em vários países latino-americanos. Essa dinâmica resultou em novos e complexos impactos e conflitos territoriais, inviabilizando, em muitos casos, os modos de vida de parte significativa da população da região. Esse contexto explicitou limitações das teorias econômicas críticas até então formuladas, levando à construção de novos paradigmas que buscavam complementar as problematizações até então formuladas e tensionar algumas de suas propostas de solução. Nesse sentido, mais do que alertar para os problemas causados por um "modelo de desenvolvimento" específico, esses novos conflitos territoriais explicitaram a necessidade de se problematizar o próprio discurso do desenvolvimento. Essa discussão se mostra cada vez mais necessária pelo cenário de constante expansão da fronteira mineral, seja para atender as demandas de infraestrutura de países emergentes (EDWARDS et al., 2014; RUBBERS, 2020), seja para garantir a transição energética de países de industrialização consolidada (BAZILIAN, 2018; CHURCH e CRAWFORD, 2020). 
Tendo por base uma ampla revisão bibliográfica, o texto é organizado em quatro partes principais, além desta introdução. Na seção 2, descrevo brevemente as principais ideias de diferentes escolas que se debruçaram sobre a relação entre extrativismo e crescimento econômico ao longo do século XX, mostrando algumas de suas conexões e relações mútuas.

A seção seguinte trata de algumas importantes questões envolvendo mineração no contexto da América Latina no início do século XXI. Essa seção é organizada em duas partes: primeiro, apresenta o contexto econômico e político da região no período 2000-2020 e, posteriormente, aborda exemplos emblemáticos de políticas públicas voltadas para o fortalecimento do extrativismo, para o enfraquecimento dos direitos territoriais e para o aumento da captura da renda mineral pelo Estado.

A quarta seção discute a natureza territorial dos conflitos que emergiram dessas políticas; mostra como eles tornaram mais claras algumas limitações das formulações críticas sobre o crescimento baseado em recursos naturais até então vigentes e, ainda, como levaram a novas proposições conceituais para se debater as relações entre ambiente, sociedade e economia.

Na seção final, são resumidos os principais aspectos dessa revisão e propostos caminhos para a elaboração de novas pesquisas e reflexões.

Recursos naturais e desenvolvimento econômico: as principais perspectivas conceituais do século XX

Ao longo desta seção, apresentam-se os principais argumentos teóricos que foram propostos em torno da relação entre recursos naturais (com ênfase nos recursos minerais) e desenvolvimento econômico. Uma discussão exaustiva sobre cada uma dessas escolas está além da proposta do texto: seu objetivo é analisar as linhas gerais que norteiam cada um dos grupos de argumentos. Apesar de se tentar adotar uma ordem cronológica para a estruturação da seção, deve-se assumir que essas escolas passaram por processos de revisão e atualização ao longo do tempo, inclusive influenciando-se mutuamente - o que torna qualquer ordem ou estrutura discricionária.

\section{A economia neoclássica}

A economia neoclássica parte de princípios teóricos como utilitarismo e equilíbrio; dessa forma ela compreende o sistema econômico a partir do indivíduo que busca maximizar seu bem-estar individual. Por isso, sua aplicação no campo da economia do meio ambiente tende a compreender os valores ambientais a partir das preferências individuais, atribuídas, principalmente, a partir de uma visão de valores de mercado (AMAZONAS, 2001; 2009).

Um subcampo da economia do meio ambiente consiste na economia dos recursos naturais. De acordo com Devarajan e Fisher (1981), as origens dessas pesquisas podem ser traçadas até o artigo de Hotelling (1931). Em seu trabalho seminal, esse último autor se propôs a estimar teoricamente o nível ótimo de extração de um recurso de forma a maximizar o ganho individual ao longo do tempo. Ele se deteve particularmente ao caso dos recursos não renováveis, considerando esse problema particularmente relevante, uma vez que a escolha se daria entre a extração imediata ou futura, considerando custos de oportunidade e valores futuros.

Em outro importante trabalho para a construção desse campo, Solow (1974) partiria da premissa de que o bem-estar seria uma função do consumo, fosse ele produzido por capital natural ou por capital manufaturado. Como ele enxergava os dois como intercambiáveis, o esgotamento dos recursos minerais não implicaria um obstáculo ao desenvolvimento, e o bem-estar das gerações futuras seria garantido se os recursos não renováveis fossem substituídos por capital reprodutível. 
Partindo desse pressuposto, ele defenderia que, sob certas condições, o mercado competitivo poderia permitir uma alocação temporal eficiente dos recursos não renováveis, uma vez que o preço dos recursos aumentaria à medida que as suas reservas se tornassem escassas. Ainda, como considerava que um recurso mineral não geraria dividendos enquanto estivesse no subsolo, a única forma de se obter valor desse recurso seria com sua extração e sua comercialização. Diante disso, o principal problema para garantir o desenvolvimento seria definir qual o momento adequado para extrair determinado recurso.

Conforme explicado por Davis e Tilton (2005), ao serem considerados um ativo de capital, os bens minerais integrariam funções de produção, juntamente com outras variáveis, tais como trabalho e capital. A partir desse entendimento, características naturais (como teor de pureza e tamanho das reservas) e tecnológicas (eficiência na transformação) definiriam a chamada renda mineral (diferença entre o preço de mercado do bem e o custo de extração). Essa renda traduziria a medida da riqueza produzida pelos agentes econômicos. Seguindo esse raciocínio, sempre que a renda mineral fosse positiva, a mineração contribuiria para o crescimento econômico dos países e, portanto, quanto mais minério fosse extraído, maior seria a riqueza gerada.

Ross (1999) argumenta que, nos anos 1950, a maior parte dos economistas que se debruçaram sobre o tema presumiam que os países pobres passavam por um desequilíbrio entre as variáveis das funções de produção (ex. grande quantidade de recursos minerais e escassez de capital para investimento). Diante disso, Rostow (1960) sugeriria como estratégia a tomada de empréstimos externos para o desenvolvimento de projetos extrativos. Além disso, faziam parte do receituário liberal a exportação dos minérios como forma de obtenção de capital e a atração de investimento direto internacional (ROSS, 1999). A alternativa de investimento direto era ainda associada à possibilidade de incorporação de novas tecnologias e ao aumento da produtividade econômica.

Em grande medida, esse discurso era acompanhado da exemplificação de casos arbitrariamente escolhidos, como Canadá e Austrália. Assim, análises eram apresentadas desconsiderando as particularidades desses países, bem como o momento histórico de seu crescimento econômico, como se fosse possível que o mesmo processo se repetisse em qualquer outro país que apostasse na exportação de recursos naturais como estratégia de crescimento (POWER, 2002).

Em resumo, conforme explica Bridge (2008), a perspectiva dos economistas neoclássicos de tratar os minérios como ativos de capital e sua tendência de preferir ganhos presentes a ganhos futuros acabaram por criar uma percepção normativa de que, salvo em situações particulares, os recursos deveriam ser extraídos o mais cedo possível para, assim, iniciar um eventual ciclo positivo de desenvolvimento.

\section{O Estruturalismo e a Teoria da Dependência}

No contexto da América Latina, as primeiras críticas à perspectiva neoclássica sobre recursos minerais e desenvolvimento econômico foram elaboradas a partir dos anos 1950. Elas foram concebidas, em grande medida, no entorno da Comissão Econômica para a América Latina e o Caribe (Cepal), a partir do debate de economistas estruturalistas e da Teoria da Dependência (GRAULAU, 2008). Embora essas teorias não tenham sido desenvolvidas para debater especificamente o papel da mineração, ambas foram muito críticas à inserção subordinada dos países periféricos no mercado global e à sua especialização na exportação de produtos básicos, dentre os quais os minerais estariam incluídos. 
O Estruturalismo tinha como uma de suas premissas básicas a ideia de que existiriam assimetrias estruturais no comércio internacional que impediriam o desenvolvimento econômico dos países periféricos. Um dos trabalhos seminais dessa teoria foi elaborado por Prebish (1949), que identificou que haveria, no longo prazo, uma deterioração dos termos de troca entre produtos básicos (agrícolas e minerais) e produtos industrializados. Segundo o autor, isso beneficiaria os países centrais no comércio internacional. Essa deterioração estaria associada a questões como baixa produtividade da mão de obra; reduzida taxa de crescimento da demanda; limitada elasticidade da demanda dos bens básicos e elevada competição entre os fornecedores de matéria-prima (SACHS e WARNER, 1995; WICK e BULTE, 2009). Diante dessa situação, para comprar a mesma quantidade de produtos manufaturados, os países periféricos necessitariam exportar quantidades crescentes de produtos básicos (SAES, 2017).

Outra contribuição importante para o pensamento estruturalista foi o conceito de dualismo estrutural, elaborado por Furtado (1965). Em sua análise, o autor identificou que, em países periféricos, haveria a convivência de dois setores bastantes distintos. De um lado, estariam setores de baixa produtividade voltados ao abastecimento do mercado doméstico. De outro, setores mais dinâmicos e com maior produtividade ligados à exportação, como a mineração e a agropecuária. A contradição dessa dualidade se daria pelo fato de esses países importarem tecnologia, contraírem dívidas e investirem em infraestrutura que privilegiaria o setor exportador, relegando a segundo plano o atendimento às necessidades nacionais e sua capacidade de aumento de produtividade em outras áreas (GRAULAU, 2008).

A Teoria da Dependência surgiu sob influência dos pensadores da Cepal e se propôs a contrapor as ideias da Teoria da Modernização, que havia sido desenvolvida por pensadores neoclássicos como Rostow (1960). Assim, ela se negaria a ver o subdesenvolvimento como fruto da incapacidade dos países periféricos em alcançar o nível de produtividade dos países centrais: a veria como resultado da própria expansão do capitalismo na periferia (COELHO, 2016).

Em um de seus trabalhos-síntese, Theotônio dos Santos (1970) definiu a dependência como uma situação em que a economia de um país é condicionada pela expansão de outro país, ao qual é subordinada. Em parte, essa situação seria fruto de relações monopolísticas de controle estrangeiro dos setores de produtos básicos, de bens de consumo e de bens de capital nos países dependentes. Esse contexto geraria um desequilíbrio no comércio entre países, resultando na transferência de excedentes dos países dependentes para os países dominantes.

Contribuindo para o debate, Cardoso e Faletto (1975) ressaltaram que, além da subordinação via relações comerciais de investimento, haveria também um componente doméstico. Os autores explicitam que a dependência é produzida também a partir de dentro, sendo conformada por relações de classe, uma vez que os sistemas produtivos dos países dependentes seriam definidos também de forma a garantir a manutenção de relações de dependência com o centro.

Os autores ainda chamam a atenção para o fato de que tais estratégias de desenvolvimento muitas vezes acabam gerando economias de enclave. Em resumo, elas se caracterizariam pela implantação de atividades econômicas estabelecidas no âmbito das necessidades dos mercados centrais, dos quais dependem para a tomada de decisão e para os quais remetem seus lucros. Ao mesmo tempo, essas atividades seriam implantadas sem conexões com a economia local - apenas com a sociedade, por meio de sistemas de poder. Em seu subtipo "enclave mineral", tais projetos se caracterizariam pela grande concentração de capital, pelo baixo nível de ocupação de mão de obra e pela limitada capacidade de distribuição de renda (CARDOSO e FALETTO, 1975).

Dessa forma, tanto os estruturalistas quanto os dependentistas construíram campos teóricos onde mostravam como o modelo neoclássico de desenvolvimento e comércio global tenderia a 
manter, ou mesmo agravar, a situação subordinada dos países periféricos. Entre os elementos-chave desse processo estavam o valor e o poder associados ao tipo de bens produzidos por cada um dos grupos de países.

\section{As Trocas Ecológicas Desiguais}

A proposta das Trocas Ecológicas Desiguais, de acordo com Roberts e Parks (2009), foi construída a partir da complexificação do debate estruturalista dos anos 1950, buscando adicionar elementos da Economia Ecológica e da Teoria Sistema Mundo.

A Economia Ecológica tem por base principal as reflexões desenvolvidas pelo economista Georgescu-Roegen (1971). Ela consiste em uma escola dentro das ciências econômicas que busca apresentar uma visão sistêmica entre meio ambiente e economia, definindo a economia como um subsistema de um ecossistema físico finito. De forma geral, a Economia Ecológica foi elaborada a partir de críticas a propostas instrumentais da valoração monetária dos serviços ecossistêmicos. Entre seus debates, estão o desenvolvimento de novas métricas para avaliação da (in)sustentabilidade (MARTINEZ-ALIER, 2002) e discussões acerca do condicionamento do pensamento econômico a limites físicos e morais (DALY e FARLEY, 2004).

De acordo com Hornborg (1998), outra teoria que foi incorporada pelos propositores das Trocas Ecológicas Desiguais foi a Teoria Sistema Mundo proposta por Wallerstein (1974; 1980; 1989). A Teoria Sistema Mundo entendia que o processo de desenvolvimento nacional não poderia ser entendido separadamente do sistema global, no qual outras nações exerciam seu poder econômico (ROBERTS e PARKS, 2009). Por esse motivo, Graulau (2008) argumenta que ela seria uma perspectiva adequada para se estudar a relação entre mineração e desenvolvimento. De acordo com a autora, a Teoria Sistema Mundo explicaria de que forma o sistema capitalista precisaria ser entendido dentro de uma extensiva divisão do trabalho, que iria além das unidades territoriais e políticas. Olhando por esse ângulo, desenvolvimento e subdesenvolvimento não seriam duas fases de um processo contínuo, mas a manifestação de uma relação de trocas desiguais de produtos caracterizados por possuírem quantidades diferenciadas de trabalho.

Ao combinar essas três perspectivas, a proposta das Trocas Ecológicas Desiguais complementa o conceito das Trocas Econômicas Desiguais, que olhava para valor exclusivamente pela métrica do salário, dos preços e do lucro. Ao lançar mão de pressupostos da Economia Ecológica, autores vinculados a essa abordagem argumentam que esse olhar puramente monetário subestima o valor da energia e dos recursos naturais embutidos em tal intercâmbio (RICE, 2007). Sendo assim, propõe-se que também seja avaliada a direção dos fluxos de material e de energia dos países periféricos para os países centrais, tomando-se o cuidado para não se cair na armadilha de se basear unicamente no valor econômico desses bens (HORNBORG, 1998).

Nesse sentido, Rice (2007) associa o início da proposta das Trocas Ecológicas Desiguais aos estudos de Bunker (1984; 1985). Embora esse último autor não dialogasse diretamente com a Economia Ecológica, ao estudar o processo de inserção global da Amazônia brasileira, particularmente a estruturação do sistema de exportação de minério de ferro, ele já alertava para o fato de que a extração de recursos naturais destruiria valores que não poderiam ser medidos em termos econômicos.

Em sua abordagem, Bunker (1985) organizou os países em economias extrativas e economias produtivas. Esses dois tipos de economias seriam distintos em termos dos efeitos que produziriam dos pontos de vista demográfico, ecológico e de infraestrutura. Ao mesmo tempo, eles possuiriam certo grau de dependência, uma vez que os bens extraídos em uma localidade seriam beneficiados 
em outras. Essa diferenciação entre economias extrativas e produtivas definiria a proporção do potencial produtivo de materiais e de energia que seria transferido dos países periféricos para os países centrais.

Monteiro e Coelho (2007), por sua vez, chamam a atenção para as contribuições de Elmar Altvater para o debate, a partir da discussão sobre trocas energéticas desiguais e degradação entrópica. Já influenciado pelas propostas de Georgescu-Roegen, Altvater (1993, p. 8) aprofundou a discussão sobre como a "[d]iminuição da sintropia por pilhagem significa o mesmo que um aumento da entropia. [E que] esta aumenta também por emissões que misturam as esferas bióticas e abióticas da terra com materiais líquidos, sólidos ou gasosos e reduzem a ordem no sentido da prontidão e da aptidão a satisfazer as necessidades dos homens". Relacionando a questão distributiva, o autor ainda argumentou que "por um lado a repartição dos recursos (ilhas de sintropia) é desigual no planeta e, por outro as cargas sobre as esferas abiótica e biótica da terra (evacuação de entropia) acontece de forma geograficamente desigual" (idem, p. 23).

Sendo assim, do ponto de vista analítico as Trocas Ecológicas Desiguais seriam explicitadas, então, pela relação inversa entre valor e potencial produtivo. Em outras palavras, o potencial produtivo de um recurso diminuiria na medida que ele fosse transformado em um produto, ao mesmo tempo em que seu valor aumentaria (HORNBORG, 1998). Portanto, a abordagem das Trocas Ecológicas Desiguais identificaria que processos como a subvaloração do fluxo de recursos naturais; a transferência de custos ambientais e a apropriação de espaço ambiental acabariam por garantir aos países centrais uma utilização desproporcional dos sistemas ecológicos, ao mesmo tempo que haveria uma imposição de danos ambientais sobre os países da periferia. Como consequência desse modelo, a existência de países periféricos, onde se concentram as atividades extrativas, intensivas no uso de recursos naturais ou na degradação ambiental, teria por função garantir o desenvolvimento econômico dos países centrais (RICE, 2007).

\section{A Maldição dos Recursos Naturais}

Rice (2007) comenta que a junção do debate da economia ambiental com a literatura sobre desenvolvimento econômico deu origem à hipótese da Maldição dos Recursos Naturais. A economia ambiental surgiu como uma proposta de reforma da economia neoclássica, em uma tentativa de, a partir da teoria econômica, propor soluções para os problemas ambientais (CAVALCANTI, 2010). Ela começou a ser formulada na década de 1960, buscando combinar elementos da economia do bemestar, da economia do crescimento e da economia política. Porém, ela só veio abarcar as questões do desenvolvimento econômico a partir dos anos 1980. Nesse contexto, pesquisadores associados à economia ambiental associam as origens dos problemas ambientais a conceitos como externalidades e falhas de mercado, e propõem soluções baseadas na valoração ambiental e em análises de custo-benefício (PEARCE, 2002).

A proposta da Maldição dos Recursos Naturais defende que economias que apresentam grande dependência de recursos naturais, particularmente petróleo e minérios metálicos, tendem a ter taxas de crescimento menores do que aquelas onde os recursos naturais possuem uma participação menor (ROSS, 1999). Wick e Bulte (2009) associam a origem desse debate a três trabalhos principais. Em primeiro lugar, eles mencionam Gelb (1988), que estudou seis países exportadores de petróleo e avaliou que as perdas econômicas durante os períodos de baixa de preços não compensavam o crescimento que ocorria nas etapas positivas dos ciclos econômicos.

Um segundo trabalho importante foi desenvolvido por Auty (1993), que estudou o comportamento de seis países periféricos (Chile, Peru, Jamaica, Bolívia, Zâmbia e Papua Nova Guiné) 
exportadores de minérios (bauxita, cobre e estanho). De acordo com ele, esses países tiveram um desempenho econômico inferior a outros países periféricos que não dependiam de minerais. Em sua pesquisa, ele defendeu que em vez de estruturar suas economias em torno da mineração, os países deveriam buscar preferencialmente a diversificação econômica.

Por fim, também fundamental foi a pesquisa de Sachs e Warner (1995). Esses autores analisaram o comportamento da economia de 97 países e identificaram que aqueles com grande participação de recursos naturais em sua pauta exportadora apresentaram taxas menores de crescimento em anos subsequentes.

A partir desses estudos iniciais, uma ampla literatura foi sendo constituída para entender quais aspectos eram responsáveis pelo comportamento identificado. Entre os fatores listados, alguns autores retornaram à questão da deterioração dos termos de troca já identificada pelos estruturalistas (ROSS, 1999).

Também foi mencionada a elevada volatilidade dos preços dos recursos minerais, que repercutiria negativamente em suas economias, tornando a balança comercial e as receitas governamentais instáveis (AUTY, 1993; DAVIS e TILTON, 2005).

Outro componente, muitas vezes chamado de Doença Holandesa, estaria associado a impactos cambiais, que repercutiriam negativamente na competitividade econômica de outros setores, levando à crescente dependência do setor extrativo exportador e à redução do dinamismo econômico local (SACHS e WARNER, 2001; WICK e BULTE, 2009).

Em contraposição a esses argumentos estruturais das economias baseadas em recursos minerais, alguns autores tentaram refutar essa hipótese, argumentando que o problema não residia na estrutura econômica desses países, mas em sistemas de "má governança". Davis e Tilton (2005, p. 239) explicam que essa visão defenderia que caso houvesse uma "boa governança", ela reduziria os riscos de rentismo e garantiria que a renda mineral seria investida de forma a "promover o desenvolvimento econômico".

Uma das limitações de trabalhos que seguem nessa linha restrita à condição de governança, como Mehlum et al. (2006), é que ela trata dos aspectos institucionais como se fossem isolados das outras características desses países. Em contraposição a tal ideia, alguns autores têm tentado avaliar até que ponto a dependência dos recursos minerais acaba por impactar negativamente a natureza dos regimes políticos (WICK e BULTE, 2009). Embora essas hipóteses sejam metodologicamente difíceis de testar (ROSS, 1999), há trabalhos como o de Leite e Weidmann (1999), que argumentam que a corrupção é determinada dentro do sistema econômico, que deve ser encarada a partir da interação entre interesses econômicos e o uso de instrumentos políticos e, ainda, que a existência de atividades extrativas intensivas em capital seria um importante determinante da corrupção.

Portanto, o que se percebe a partir da leitura sobre a Maldição dos Recursos Naturais é que, mesmo tendo suas origens na perspectiva reformista da economia ambiental, ela se mostra majoritariamente crítica ao papel dos recursos naturais no desenvolvimento econômico dos países periféricos.

\section{As Redes Globais de Produção e seu olhar sobre o setor extrativo}

A proposta das Redes Globais de Produção (RGPS) foi elaborada principalmente a partir do olhar da geografia econômica em uma discussão ampla sobre desenvolvimento. Conforme alertam Santos e Milanez (2015), o modelo das RGPs se mostra como uma estratégia promissora para analisar as relações entre globalização, sistemas de produção e crescimento econômico. Portanto, 
ele se distingue das escolas anteriores por não ter sido concebido exclusivamente dentro do debate das ciências econômicas e por não ser específico para o estudo do papel dos recursos naturais.

Apesar disso, sua inserção nesta revisão pareceu pertinente pelo fato de avançar em alguns pontos não tratados pelas escolas anteriores, especialmente por romper com o Estado-nação como unidade de análise. A Teoria da Dependência já chamava a atenção para o controle transnacional das corporações extrativas. Além disso, trabalhos vinculados à Maldição dos Recursos Naturais destacavam aspectos da relação Estado-corporações (BRIDGE, 2008). Esses elementos, porém, não chegaram a ser centrais nessas formulações teóricas. Por esses motivos, ao deixar de enxergar os Estados como estruturas políticas independentes, o olhar das RGPs se mostrou como estratégia consistente para encará-los como manifestações políticas das redes de produção (GRAULAU, 2008). Mais do que isso, devido ao seu caráter multiescalar, esse conceito permitiria a avaliação em nível nacional ou subnacional (MILANEZ e SANTOS, 2019).

A abordagem das RGPs define a globalização econômica por meio da constituição de sistemas transnacionais de extração de matérias-primas, produção de bens e oferta de serviços - sejam eles intermediários ou finais. Esses sistemas transnacionais, funcionalmente integrados e territorialmente dispersos (COE et al., 2008) constituiriam, por excelência, o veículo do processo de desenvolvimento econômico dos países.

De forma sintética, o modelo avalia a atuação de agentes-chave, que incluem empresas, Estado, trabalhadores e movimentos sociais, entre outros. A avaliação da relação entre esses agentes se daria a partir de três categorias conceituais: valor (criação, ampliação, captura e destruição); poder (corporativo, institucional e coletivo) e enraizamento (territorial, social, em rede e material). Em termos gerais, as condições de enraizamento influenciariam o grau de poder dos agentes, que definiria sua capacidade de gerar, ampliar e capturar valor (HENDERSON et al., 2002; COE et al., 2008; SANTOS e MILANEZ, 2015).

Apesar de não ter sido construído especificamente para lidar com o debate sobre o papel dos recursos naturais no crescimento econômico, o modelo das RGPs se mostrou plástico o suficiente para contribuir com essa discussão. Dentro dessa perspectiva, o estudo sobre a relação entre atividades extrativas e desenvolvimento econômico passaria a ser entendido a partir de uma avaliação relacional entre esses agentes e de como eles se organizam (BRIDGE, 2008). Considerando aspectos específicos do setor mineral, particularidades como a ampliação do valor pela incorporação de energia e soluções logísticas, a apropriação de valor por meio de processos de acumulação por espoliação e a destruição de valor pela degradação ambiental (SANTOS e MILANEZ, 2015) passam a ser determinantes para se discutir o desenvolvimento dos países e regiões.

Esse olhar relacional, então, explicitaria a tensão existente entre os diferentes agentes integrantes de uma rede. Tal tensão surgiria, por exemplo, entre corporações e movimentos sociais em torno da definição do controle territorial, uma vez que o acesso ao subsolo pelos primeiros inviabilizaria as atividades de produção e reprodução das comunidades existentes. Ao mesmo tempo, haveria disputa - entre as transnacionais extrativas e o Estado - pela apropriação da renda mineral extraída.

Dessa forma, considerando sua perspectiva analítica, a proposta das RGPs não definiria, a princípio, a capacidade de uma atividade em proporcionar desenvolvimento econômico para uma região. Ao contrário, ela entenderia que isso dependeria das relações analisadas, que permitiriam ou restringiriam as possibilidades de acoplamento estratégico. Entretanto, no contexto do setor extrativo, estudos específicos sugerem oportunidades limitadas para a geração de desenvolvimento econômico, seja no caso do petróleo (BRIDGE, 2008), seja na extração de minério de ferro (SANTOS e MILANEZ, 2015; MILANEZ e SANTOS, 2018; 2019) ou de nióbio (GONÇALVES e MILANEZ, 2020). 
Em resumo, a breve descrição apresentada mostra a riqueza teórica que foi fomentada pelo estudo da relação entre recursos naturais e desenvolvimento econômico ao longo do século XX. O debate se coloca para além da dicotomia ortodoxos versus heterodoxos. O que se percebe é que a partir da visão normativa liberal construíram-se várias propostas críticas, em maior ou menor grau de radicalidade. Ao mesmo tempo, esse posicionamento crítico apresentou importantes divergências, que enriqueceram ainda mais o debate. Todavia, como será discutido na próxima seção, apesar da complexidade e da solidez de elaborações como Teoria da Dependência, Estruturalismo, Trocas Ecológicas Desiguais e Maldição dos Recursos Naturais, bem como de estudos críticos específicos no contexto das RGPs, o poder da narrativa liberal manteve-se presente no ideário de governantes e de parte da sociedade latino-americana, tendo retornado com bastante força no início do século XXI.

\section{O neoextrativismo e seus efeitos sobre as políticas públicas}

\section{Neoliberalismo, globalização e a emergência da Ásia}

A construção da Teoria da Dependência e do pensamento estruturalista teve forte impacto sobre as políticas econômicas dos países da América Latina entre os anos 1950 e 1970, dando origem ao modelo de industrialização via substituição de importações. À época, os países buscavam criar uma estrutura produtiva que Ihes permitisse implantar uma base industrial e reduzir a importação de produtos manufaturados. Essas políticas eram baseadas, em grande parte, no endividamento externo, nos investimentos diretos internacionais e na intervenção do Estado. Nesse processo, tinham papel especial, ainda, as empresas estatais, particularmente nos setores extrativistas (SIKKINK, 1991).

Esse modelo, porém, enfrentou certo desgaste a partir da década de 1970, especialmente devido ao crescente endividamento público, que se tornou insustentável com a elevação das taxas de juros internacionais em 1979, resultante da nova política monetária restritiva norte-americana (MATTEI e SANTOS JÚNIOR, 2009).

Mudanças importantes nas políticas econômicas ocorreram a partir dos anos 1980, quando foi adotada uma reorientação das estratégias para o pagamento das dívidas. Esse movimento teve grande influência dos programas de ajuste estrutural promovidos, especialmente, pelo Fundo Monetário Internacional e pelo Banco Mundial de cunho profundamente neoliberal. Esses programas foram aprofundados, ao longo dos anos 1990, no que se convencionou chamar Consenso de Washington. Dentro dessa visão, governos eram vistos como facilitadores para investimentos externos e, para tanto, deveriam garantir estabilidade institucional, reduzir riscos econômicos e facilitar a captura da renda mineral pelas empresas internacionais. No setor mineral, especificamente, essas mudanças consistiram na aprovação de leis liberalizantes que incluíam a redução da intervenção do Estado na economia, a privatização de companhias estatais e a facilitação para investimentos estrangeiros (GRAULAU, 2008; SVAMPA, 2013a), conforme apresentado na Tabela 1. 
Tabela 1 - Mudanças institucionais de cunho neoliberal na América Latina, países selecionados

\begin{tabular}{|c|c|c|}
\hline País & $\begin{array}{l}\text { Mudanças visando ao estímulo à } \\
\text { atividade privada na mineração }\end{array}$ & $\begin{array}{c}\text { Mudanças permitindo/facilitando investimentos estrangeiros } \\
\text { nos países (genéricos ou em mineração) }\end{array}$ \\
\hline Argentina & $\begin{array}{l}\text { Ley 24.498/1995 de Actualización } \\
\text { Minera }\end{array}$ & $\begin{array}{c}\text { Texto ordenado de la ley } 21382 \text { sobre inversiones extranjeras } \\
\text { (Decreto } N^{\circ} 1853 / 1993 \text { ) }\end{array}$ \\
\hline Brasil & \multicolumn{2}{|c|}{ Emenda Constitucional 6/1995 } \\
\hline Bolívia & $\begin{array}{l}\text { Código de Minería } \\
\text { (Ley } 1.777 / 1997)\end{array}$ & $\begin{array}{l}\text { Ley de Inversiones } \\
\text { (Ley } 1.182 / 1990)\end{array}$ \\
\hline Chile & $\begin{array}{l}\text { Código de Minería } \\
\text { (Ley 18.248/1983) }\end{array}$ & $\begin{array}{l}\text { Estatuto de la Inversión Extranjera } \\
\text { (Decreto Ley 600/1976) }\end{array}$ \\
\hline Equador & $\begin{array}{l}\text { Ley de Minería } \\
\text { (Ley } 126 / 1991 \text { ) }\end{array}$ & $\begin{array}{l}\text { Ley } 12 \text { de Cámaras de Minería } \\
\text { (Decreto No 415/1993) }\end{array}$ \\
\hline Peru & $\begin{array}{c}\text { Ley General de Minería } \\
\text { (Decreto Legislativo 109/1992) }\end{array}$ & $\begin{array}{l}\text { Ley de Promoción de la Inversión Privada (Decreto Legislativo } \\
\qquad 757 / 1991)\end{array}$ \\
\hline Venezuela & $\begin{array}{c}\text { Decreto con rango y fuerza de ley de } \\
\text { minas } \\
(295 / 1999)\end{array}$ & $\begin{array}{l}\text { Regulación de la inversión extranjera } \\
\text { (Decreto 2095/1992) }\end{array}$ \\
\hline
\end{tabular}

Fonte: O autor a partir de Chaparro (2002)

Esses países, então, passaram por um processo de rápida redução do tamanho do Estado e de uma inversão nas estratégias de desenvolvimento econômico. O foco no mercado interno foi reduzido, adotou-se a preocupação com o crescimento para o exterior, e a exportação voltou a ser vista como "nova" estratégia de desenvolvimento (BARTON, 2006). Devido à recessão pela qual passavam a América do Norte e a Europa Ocidental, os anos 1980 e 1990, conforme demonstrado no Gráfico 1, foram um período de baixa histórica dos preços das commodities (GRAULAU, 2008). Mesmo assim, esses produtos compuseram a base da inserção internacional dos países da região, dada a falta de competitividade dos bens industrializados (ALBAVERA, 2004).

Dessa forma, a adoção das premissas neoliberais levou a uma especialização da região na comercialização de produtos intensivos em recursos naturais, com valores significativamente depreciados. Esse, porém, foi um dos principais caminhos encontrados para garantir a entrada das divisas necessárias para permitir a importação de bens intensivos em tecnologia (SCHAPER e VÉRÈZ, 2001).

O cenário do comércio global se modificou, porém, no início dos anos 2000, a partir do aumento da participação da China no comércio internacional. Dentro de uma nova lógica de crescimento, a China passou a atuar como um dos principais centros industriais do mundo, tanto transformando grande quantidade de matéria-prima em produtos para exportação quanto realizando grandes obras internas de infraestrutura (SAES, 2018). O crescimento na demanda por commodities minerais, aliado à especulação de crescimento futuro, teve um impacto combinado sobre os preços desses produtos, levando a patamares extremamente valorizados durante o período 2003-2011, como apresentado no Gráfico 1. 
Gráfico 1 - Variação do preço real de minerais industriais (número índice)

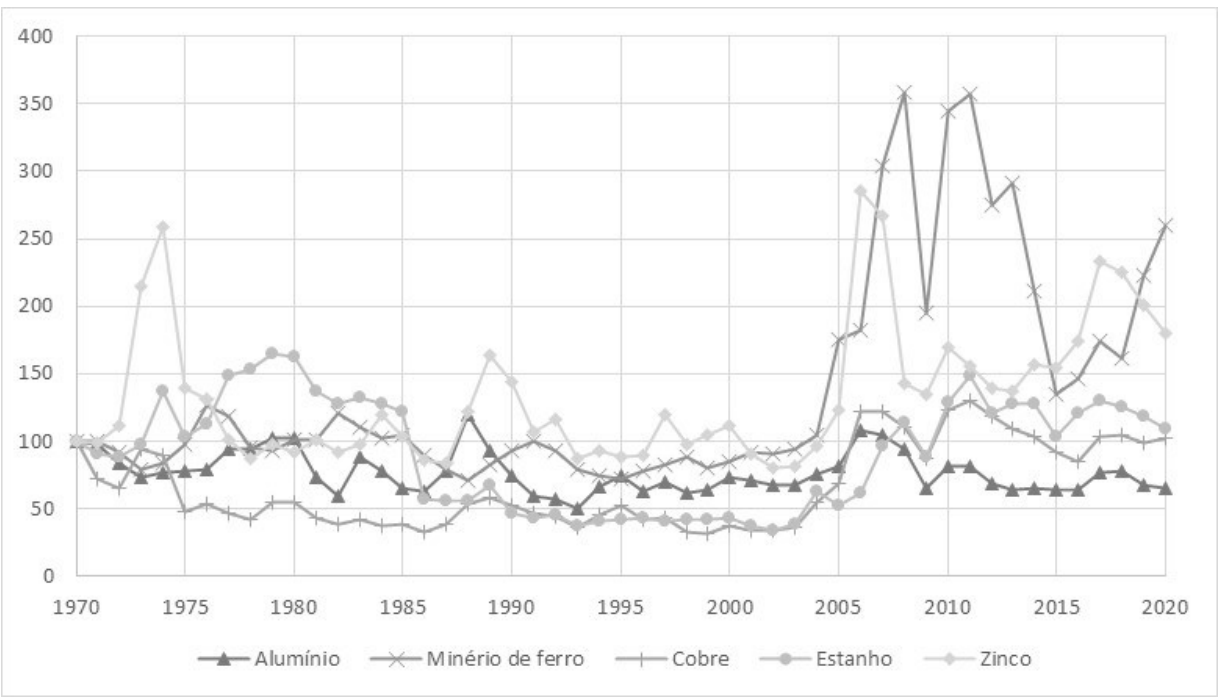

Fonte: O autor a partir de The World Bank (2021)

Conforme discutido na seção sobre Maldição dos Recursos Naturais, o preço das commodities minerais é caracterizado por elevada volatilidade; existem tanto pequenas oscilações quanto ciclos mais longos de elevação e queda nos preços. Ao avaliar as flutuações dos anos 2000, Cooney et al. (2008) apresentaram duas explicações que se complementariam na influência desse processo. De um lado, existiriam mudanças nos fundamentos econômicos do mercado físico mundial, particularmente associadas à relação entre oferta e demanda. De acordo com essa hipótese, teria ocorrido um choque de demanda decorrente do aumento de consumo. Ainda seguindo esse raciocínio, a redução na taxa de crescimento chinês, a partir do início dos anos 2010, teria levado à redução dos preços. Por outro lado, uma segunda explicação estaria associada à crescente financeirização do setor de commodities. Nesse sentido, a elaboração de instrumentos financeiros cada vez mais complexos e diversificados, bem como o crescimento dos fundos de índice de commodities, teria causado uma bolha especulativa, levando a preços artificialmente elevados no mercado físico. A partir de 2012, com a redução da expectativa de ganhos, tais operadores do mercado financeiro teriam migrado para outras opções, levando à queda abrupta dos preços (MILANEZ, 2017).

Apesar da queda significativa dos preços das commodities a partir de 2012, os 10 anos de boom mostraram aos agentes econômicos que, no novo contexto global de expansão asiática, seria possível obter elevadas taxas de lucratividade. Ao mesmo tempo, a efemeridade desses lucros deixou de assustar investidores, já acostumados com a volatilidade do sistema financeiro. Além disso, a possibilidade de novos ganhos extraordinários - a partir do aumento da demanda por minerais estratégicos para garantir a transição energética dos países centrais (KLARE, 2012) - criou uma expectativa de possíveis novos ciclos de alta demanda, mantendo mobilizada parte da estrutura tecnológica, social e política que foi criada durante a primeira década do século XXI.

Dessa forma, a brusca variação dos preços nos anos 2000 teve como consequência não apenas a consolidação da centralidade do setor extrativo na economia dos países da América Latina, mas também o aprofundamento da dependência desses países em relação à exportação de matéria- 
prima. Esse processo e seus impactos nas políticas públicas territoriais são discutidos em mais detalhes nas próximas seções.

\section{"Novas" estratégias de crescimento: o extrativismo de volta ao centro}

Dentro da literatura latino-americana, essa "nova etapa" da política de crescimento é comumente denominada como neoextrativismo; um modelo de desenvolvimento focado no rápido crescimento econômico e baseado na apropriação de recursos naturais, em redes produtivas pouco diversificadas e na inserção internacional subordinada. O conceito normalmente se refere à extração de recursos minerais e de petróleo, bem como atividades agrárias, florestais e de pesca (ACOSTA, 2011; GUDYNAS, 2012a; c). Ele descreve empreendimentos estruturados em enclaves voltados para a exportação, com baixo encadeamento econômico e com grande fragmentação social e regional (SVAMPA, 2013a).

Gudynas (2015) diferencia duas variações principais do neoextrativismo. De um lado, estaria o neoextrativismo conservador reajustado. Até certo ponto, ele seria um aprofundamento do modelo extrativista clássico desenvolvido nos anos 1980-1990, e estaria presente em nações governadas por grupos de centro-direita nos anos 2000, como Colômbia, Peru e México. Nesses países, teriam ocorrido ajustes para reduzir o controle social e as normas ambientais, de forma a facilitar ainda mais os investimentos internacionais nos setores extrativistas. Dentro dessa narrativa, a ausência do controle público sobre as empresas extrativas não seria um problema, uma vez que sistemas voluntários e práticas de responsabilidade social corporativa seriam suficientes para superar conflitos criados por essas atividades.

Por outro lado, o autor identificou o desenvolvimento de um "neoextrativismo progressista" entre os países que aderiram, nos anos 2000, à "onda rosa" na região (ex. Argentina, Bolívia, Brasil, Equador e Venezuela). Nesse modelo, o Estado teria um papel diferente e seria responsável por controlar o acesso aos recursos naturais, fosse por meio da regulação, da nacionalização das reservas ou da atuação de companhias estatais. Outro elemento essencial dessa forma de extrativismo seria o papel do "Estado compensador", que capturaria parte das rendas extrativas para implantar programas de combate à pobreza e diminuir as desigualdades sociais. Essa versão "progressista" também negaria os impactos sociais e ambientais de tais atividades e, em alguns casos, o combate à desigualdade social acabaria sendo usado como discurso para legitimar os projetos extrativistas (GUDYNAS, 2012a; c; 2015).

A visão hegemônica sobre a centralidade do extrativismo como estratégia de crescimento econômico fez com que Svampa (2013a) argumentasse que a América Latina havia substituído o "Consenso de Washington", baseado na valorização financeira, pelo "Consenso das Commodities", centrado na exportação de bens primários em grande escala. Para a autora, ideias como "oportunidades econômicas" e "vantagens comparativas" transbordaram as fronteiras políticoideológicas erguidas nos anos 1990. Assim, mesmo nos governos ditos de esquerda, a visão neoextrativista consistiria na resignação com um "capitalismo progressista" e na aceitação de que não existiriam outras alternativas ao "desenvolvimento extrativista".

A ideia de consenso proposta por Svampa (2013a) foi reformulada por Slipak (2014), que tentou tornar a componente geopolítica ainda mais explícita ao propor o "Consenso de Pequim". De acordo com o autor, essa proposta se refere à ideia de que o aprofundamento das relações comerciais com a China havia se tornado um "caminho inevitável" para o crescimento econômico da região. A visão consensual se manifestaria a partir de estratégias de "cooperação", que seriam marcadas por um padrão de subordinação e dependência. Tais estratégias seriam adotadas tanto por governos 
conservadores, a partir de uma visão liberal de comércio exterior, quanto por governos ditos "progressistas", que as defenderiam baseados na justificativa do rompimento com as hegemonias tradicionais, como EUA e Europa.

As relações entre América Latina e China se dariam por diferentes caminhos: trocas comerciais de matéria-prima latino-americana por produtos industrializados chineses, investimentos externos diretos ou acordos de livre comércio. Ao mesmo tempo, haveria uma certa adaptação de estratégias aos contextos locais; por exemplo, enquanto no Peru e no Equador a atuação se daria diretamente por mineradoras chinesas, no Brasil a entrada se daria por meio da participação no capital de empresas de mineração nacionais. Assim, os vínculos criados seriam baseados em vantagens comparativas estáticas tradicionais, bem como na complementaridade econômica, o que viria a se configurar como "neodependentismo" (SLIPAK, 2014; SVAMPA e SLIPAK, 2015).

A orientação neoextrativista da estratégia de crescimento da região se mostrou bastante resiliente. Mesmo com a queda dos preços dos minérios após 2012 (Gráfico 1), a importância dos minerais continuou a crescer na pauta exportadora dos países. Assim, entre 2010 e 2018, a quantidade exportada de minério de ferro pelo Brasil cresceu 25\%. No mesmo período, a exportação de cobre aumentou em 570\% no Chile e 366\% no Peru. De forma semelhante, a venda de ouro para consumidores globais aumentou 1.556\% no Chile, 226\% no México e 130\% na Argentina (ITC, 2021). Para garantir esse crescimento, alterações importantes ocorreram nas políticas públicas, promovendo um aprofundamento da espoliação de terras, territórios e bens naturais (SVAMPA, 2013a), conforme descrito na próxima seção.

\section{Consequências políticas e para os territórios}

A elevação momentânea dos preços das commodities e a perspectiva da sua exportação como fonte de renda rápida acabou criando um cenário de convergência de interesse entre empresas mineradoras e Estados nacionais. Dentro desse contexto, foram criadas parcerias tácitas na formulação de políticas públicas ambientais e territoriais, que tiveram impactos no papel do Estado, na construção da legitimidade das atividades extrativas, na gestão de conflitos e desastres, na (não) remediação de áreas impactadas e na saúde dos trabalhadores. Em grande parte, essas políticas tinham como objetivo principal estimular e facilitar a atividade do setor extrativo nesses países.

Um elemento importante desse processo foi a institucionalização das parcerias entre o setor regulado (as mineradoras) e o setor regulador (o Estado) na formulação das políticas públicas. Por exemplo, na Colômbia, o Canadian Energy Research Institute (uma organização vinculada a empresas de base mineral e energética) foi uma das instituições que participou ativamente nas alterações das legislações ambiental, mineral e de petróleo, no início dos anos 2000 (GORDON e WEBBER, 2016).

De forma semelhante, quando o Poder Executivo brasileiro fez as propostas de alteração do seu Código Mineral, todos os cargos de diretoria da Secretaria de Geologia e Transformação Mineral do Ministério de Minas e Energia eram ocupados por ex-funcionários ou ex-consultores de empresas mineradoras (MILANEZ et al., 2017).

A partir de tais alianças, passou-se, em grande parte, a defender a instalação de sistemas de governança, nos quais parte das obrigações do Estado seria transferida para as empresas mineradoras. Por exemplo, no caso do Peru, Bebbington (2010) identificou que à medida que as indústrias mineradoras instalavam suas atividades em áreas remotas, passavam a assumir os papéis normalmente atribuídos ao Estado, como de planejamento territorial, gestão de conflitos e oferta de serviços públicos. $\mathrm{O}$ autor notou ainda que tais iniciativas iam além da esfera imediatamente vizinha às minas e poderiam incluir ações de cunho regional, ou mesmo nacional, por meio de articulações 
interorganizacionais. Todo esse processo teria como resultado maior legitimação das empresas mineradoras e crescimento da aceitação dos projetos extrativos.

Um caso extremo dessa transferência foi identificado no Brasil, após o rompimento da barragem de Fundão da mineradora Samarco S.A. em 2015. De acordo com Santos e Milanez (2017), esse caso apresentou elementos da transição de um modelo "fraco" de regulação estatal para a autorregulação. Segundo os autores, a constituição da Fundação Renova e a transferência para ela das responsabilidades de identificar pessoas atingidas e definir o valor das indenizações, entre outras (cf. MILANEZ et al., 2021), acabou por estabelecer um regime de regulação capturada (MATTLI e WOODS, 2009).

A ampliação da expropriação de territórios para garantir a expansão das atividades extrativas a partir dos anos 2000 acabou por intensificar os conflitos territoriais na região. Ao analisar os dados compilados por EJOLT (2016) até 2016, González (2019) identificou que, dos 526 conflitos ambientais localizados na América Latina, cerca de 40\% envolviam projetos de mineração. Segundo o autor, esses conflitos eram derivados principalmente dos impactos sobre o território, do uso desigual de recursos naturais, de expectativas não cumpridas sobre a distribuição dos benefícios dos projetos, de diferentes cosmovisões e perspectivas de modelos de desenvolvimento e da falta de capacidade do Estado em regular o setor.

Ainda segundo González (2019), como forma de lidar com esse aumento dos conflitos, os governos passaram a adotar métodos de resolução de conflitos baseados na mediação e na arbitragem. Ele explica que tais instrumentos seriam legitimados pelo discurso de que permitiriam que se encontrasse "alternativas mutuamente benéficas para as comunidades, para as empresas e para as instituições públicas" (p. 368). Todavia, Viegas et al. (2014) alertam para o fato de que a principal justificativa para esse modelo de resolução de conflitos seria a busca da eficiência, da eficácia e da celeridade. Nesse sentido, Ferreira (2020) explica que a adoção desses instrumentos buscaria desqualificar a esfera jurisdicional, reforçando o princípio de um Estado mínimo, defendido pelos cânones neoliberais. Assim, para a autora, uma das principais motivações para a adoção desses instrumentos seria a redução de custos (para empresas e Estado) e não a reparação integral das pessoas atingidas. Dessa forma, um de seus resultados seria a construção de uma "harmonia coercitiva" (NADER, 1990), garantindo a aceitação dos projetos.

Dentro do debate sobre conflitos e negociação, um aspecto que ganhou especial atenção ao longo das últimas décadas na região dizia respeito ao processo para se alcançar acordos sobre a liberalização de atividades extrativas em territórios indígenas. A normatização mais avançada sobre o tema estabelece a necessidade de consentimento dos povos indígenas. Por exemplo, a Declaração das Nações Unidas sobre os Direitos dos Povos Indígenas (ONU, 2008) e a Declaração Americana sobre os Direitos dos Povos Indígenas (OEA, 2016) estabelecem que antes de conceder a autorização de atividades extrativas, os Estados precisam obter consentimento livre e informado desses povos. Todavia, essas normas são não vinculantes e, raramente, seguidas. Em um estudo realizado por Aranibar et al. (2011), foi avaliada a legislação sobre atividades extrativas em terras indígenas na Bolívia, na Colômbia, no Peru e no Equador. Nesses quatro países, o arcabouço legal se limitava a seguir a Convenção 169 da Organização Internacional do Trabalho, que prevê apenas a consulta a esses povos (OIT, 2011), ignorando a necessidade de consentimento. Dessa forma, a ideia de consulta, sem a possibilidade de veto, indica a retirada do poder de decisão dos povos indígenas e a transformação de sua participação em um processo meramente burocrático.

A expansão em número e tamanho dos projetos extrativos na América Latina chamou a atenção para os problemas associados a passivos ambientais da mineração, sejam minas abandonadas ou com atividades paralisadas sem as devidas ações de controle ambiental. Passivos 
nessa situação apresentam um potencial ainda maior de ameaça à segurança das comunidades e do meio ambiente. De acordo com Miguel e Pereira (2019), existe um amplo desconhecimento do problema na região; poucos países possuem inventários regularmente atualizados, e estudos pretéritos identificaram 449 passivos ambientais da mineração na Colômbia (2015), 492 no Chile (2014), 973 na Bolívia (2011) e 8.854 no Peru (2016).

Essa situação, em grande parte, seria consequência da decisão das empresas de abandonar as áreas, ou decretar falência, quando os projetos não se mostravam mais rentáveis; aliada à baixa fiscalização dos governos. Uma das formas de se tentar evitar que minas em operação venham a ser abandonadas posteriormente é a exigência de garantias financeiras por parte das empresas (ex. fundos fiduciários, carta de crédito ou seguros). Todavia, esse é um instrumento pouco usado na região e os autores mencionam esse tipo de experiência apenas na Argentina, no Chile e no Peru.

A aproximação dos interesses privados e dos governamentais pela garantia da manutenção das atividades extrativas também parece se sobrepor à proteção da saúde dos trabalhadores. Com a emergência da pandemia de Covid-19, muitos foram os riscos identificados para os trabalhadores (BAINTON et al., 2020; CASTRO, F. F. et al., 2020). Apesar disso, pouco mais de um mês após os primeiros alertas da doença na América Latina, os governos de Argentina, Brasil, Chile, Colômbia e Equador, entre outros, declararam a mineração como atividade essencial (BNAMERICAS, 2020), impedindo que as operações fossem interrompidas e que houvesse perdas econômicas para as empresas.

Talvez o único campo onde se constituiu alguma divergência entre empresas e governos foi na disputa pela renda mineral. Ao longo dos anos 2000, foi possível ver a ascensão do chamado nacionalismo de recursos, definido por Haslam e Heidrich (2016a) como "uma grande variedade de ações e políticas pelas quais o Estado busca aumentar sua influência sobre o desenvolvimento do setor de recursos minerais". Ainda segundo os autores, sua manifestação poderia ocorrer a partir de três categorias de ações: "a maximização da receita pública, a garantia do controle estatal estratégico [...] e o aumento do transbordamento do desenvolvimento das atividades extrativas". A Tabela 2 ilustra algumas das iniciativas legais implementadas com esses objetivos:

Tabela 2 - Mudanças legais visando à apropriação da renda extrativa na América Latina, países selecionados

\begin{tabular}{|c|c|}
\hline País & Mudanças legais \\
\hline Argentina & Nacionalização do controle acionário da YPF (Ley 26.741/2012) \\
\hline Brasil & $\begin{array}{c}\text { Definição do modelo de partilha da produção do Pré-sal (Lei 12.351/2010) } \\
\text { Modificação da base de cálculo dos royalties da mineração (Lei 13.540/2017) }\end{array}$ \\
\hline Bolívia & $\begin{array}{c}\text { Criação do Imposto Direto sobre Hidrocarbonetos (Ley 3.058/2005) } \\
\text { Nacionalização dos hidrocarbonetos (D.S. No 2.8701/2006) }\end{array}$ \\
\hline Chile & Criação do novo regime tributário do imposto específico para a renda operacional da atividade mineira \\
(Ley 20.469/2010)
\end{tabular}

Fonte: 0 autor a partir de Viale e Cruzado (2012)

Ainda de acordo com Haslam e Heidrich (2016b), no contexto latino-americano, a manifestação do nacionalismo de recursos poderia ser identificada em sua modalidade radical (Bolívia e Venezuela), moderada (Brasil e Peru) e limitada (Colômbia e México). Para os autores, três grupos de fatores atuaram para motivar e possibilitar esse movimento: o preço das commodities; as mudanças na dinâmica de integração internacional dos países (comércio internacional e investimentos diretos) e aspectos setoriais (existência e qualidade de reservas, participação dos setores extrativistas nas 
economias nacionais, entre outros). Dependendo desses fatores e das capacidades institucionais dos governos, esses conseguiriam capturar maior ou menor renda das corporações extrativas.

Em resumo, o processo de abertura da economia e especialização em exportação de matérias primas que marcou os anos 1990 na América Latina se aprofundou consideravelmente a partir dos anos 2000. A possibilidade de ganhos significativos levou a alianças entre Estado e empresas em várias frentes de políticas públicas visando ao aumento da captura da renda mineral. Esse processo consensuado, porém, ampliou o surgimento de conflitos nos territórios onde os projetos extrativos se implantavam (SVAMPA, 2013a). Como consequência, novas alianças organizativas foram construídas e debates sobre o uso dos bens comuns e o conceito de desenvolvimento ganharam centralidade entre os movimentos sociais. Alguns desses elementos são descritos na próxima seção.

\section{A construção do pós-extrativismo}

O aprofundamento do modelo extrativista ampliou e intensificou conflitos sociais, ambientais, políticos e culturais tendo como centro a defesa da natureza, dos territórios e dos recursos naturais (SVAMPA, 2013a; b). Em grande parte, esses conflitos se aproximavam das questões trazidas pela Ecologia Política, uma vez que eram associados a modificações no acesso e no controle político sobre a natureza, bem como à sua definição social e cultural (BURCHARDT, 2016).

Esses conflitos resultaram em uma aproximação maior entre movimentos sociais, organizações ambientalistas, comunidades campesinas e povos tradicionais na construção de novas visões da natureza, direitos territoriais e mesmo de progresso (SVAMPA, 2013b). Como resultado, houve o crescimento de organizações nacionais e regionais na América Latina que elegeram o setor extrativo como sua pauta principal.

No Brasil, podem ser citados o Movimento pela Soberania Popular na Mineração, o Comitê em Defesa dos Territórios frente à Mineração e a Articulação das Atingidas e Atingidos pela Vale. Em outros países latino-americanos, são exemplos a Red Mexicana de Afectados por la Minería (México), o Observatório de Conflictos Mineros de América Latina (regional), a Red Iglesias y Minería (regional) e a Alianza Centroamericana Frente a la Minería Metálica (regional). Além desses, outros movimentos já existentes deram mais centralidade à discussão e à elaboração crítica de atividades extrativas em suas pautas, tais como Centro de Documentación e Información Bolivia (Bolívia), Observatorio Latinoamericano de Conflictos Ambientales (Chile), Censat Agua Viva (Colômbia), Acción Ecológica (Equador) e CooperAcción (Peru) (OCMAL, 2021).

A adoção do "neoextrativismo progressista" por países da região gerou uma considerável decepção entre movimentos sociais com os rumos tomados pelos "governos de esquerda". Essas frustrações se deram tanto no campo prático das políticas públicas quanto na esfera das concepções e ideologias.

Do ponto de vista das políticas públicas, o que se percebeu foi a falta de mudanças verdadeiras na estrutura socioeconômica desses países. Apesar de o modelo ter garantido alguma distribuição de renda durante o período de alta dos preços das commodities, não foram realizadas alterações que garantissem a redistribuição da riqueza. Por exemplo, não ocorreram modificações significativas nas estruturas tributárias ou fundiárias. Em alguns casos, essas políticas chegaram a intensificar aspectos de desigualdade, fosse pelo incentivo fiscal a projetos extrativistas, fosse pela concentração da terra nas mãos de projetos do agronegócio ou de extração mineral. Em parte, com o fim do ciclo de alta dos preços, medidas compensatórias foram reduzidas e, consequentemente, esses governos perderam parte de seu apoio social (PETERS, 2016). 
Todavia, mais crítico foi o aprofundamento do debate conceitual, particularmente em torno do entendimento de significados como prosperidade, progresso e desenvolvimento. Ao abraçar o "neoextrativismo progressista" como estratégia de crescimento rápido, esses governos não questionaram suficientemente as estruturas de poder e de dominação presentes em tal modelo (PETERS, 2016). Em parte, isso seria explicado pelo fato de a esquerda latino-americana, em geral, ter sido fortemente marcada pelo desenvolvimentismo, e por ter como referências para a mudança social o crescimento econômico a expansão das forças produtivas, a modernização e o industrialismo (SVAMPA, 2013b; 2018).

Simultaneamente, dada a explicitação do caráter territorial dos conflitos que emergiram ao longo das primeiras décadas dos anos 2000, também foi sendo percebida a insuficiência das teorias críticas de crescimento econômico que foram elaboradas ao longo do século XX. De certa maneira, essas escolas foram caracterizadas por uma forte concepção ocidental de desenvolvimento, centrado no crescimento econômico e no Estado nacional ${ }^{4}$ (BURCHARDT, 2016). Dentro desse limite, elas deixavam de identificar efeitos socioecológicos em escala subnacional, ou impactos diferenciados no modo de vida de grupos sociais específicos, como mulheres, indígenas, negros, entre outros (PETERS, 2016).

Ao mesmo tempo, a visão de desenvolvimento dessas escolas separava a natureza e a sociedade, minimizava os impactos socioambientais e apresentava um considerável otimismo tecnológico (GUDYNAS, 2017). Em termos gerais, o receituário para a superação dos problemas identificados por elas passava pela verticalização ou pelo adensamento de cadeias produtivas, pela agregação de valor e pela industrialização. Se isso fazia sentido em algumas situações, dentro do novo contexto político-econômico e da expansão territorial dos projetos extrativistas, algumas dessas "soluções" aprofundavam ainda mais os impactos e os conflitos, como, por exemplo, a implantação de siderúrgicas ao longo da Estrada de Ferro Carajás, na Amazônia brasileira (MONTEIRO, 2005).

Na construção de um novo entendimento sobre esses processos, teve especial importância o campo do pós-desenvolvimento, em grande parte influenciado pelos estudos de Escobar (1995). De acordo com o autor, seria necessário pensar no "desenvolvimento" em termos de discurso, o que permitiria explicitar sua capacidade de exercício de poder e de propagação ideológica no "Terceiro Mundo". Assim, ele propôs definir o desenvolvimento como um instrumento de domínio do pensamento e da ação, e analisou como ele seria caracterizado por três eixos principais: formas de conhecimento, sistemas de poder e formas de subjetividade (que fariam com que os povos se reconhecessem como "desenvolvidos" ou "subdesenvolvidos").

Dessa forma, segundo Escobar (1995), a realidade teria sido colonizada pelo discurso do desenvolvimento, cabendo aos insatisfeitos lutar por migalhas de liberdade dentro do sistema, na esperança de que no processo outra realidade pudesse ser construída. Portanto, para romper com esse ciclo, não seria mais suficiente buscar "desenvolvimentos alternativos", mas sim construir "alternativas ao desenvolvimento", que levassem em conta os conhecimentos e culturas locais, adotassem perspectivas críticas a discursos exclusivamente positivistas, e promovessem movimentos locais e plurais.

Svampa (2013a) argumenta que a construção do pós-desenvolvimento estaria baseada em três desafios fundamentais: avançar na construção de um "horizonte de desejabilidade", identificar

\footnotetext{
4 Embora a proposta das Trocas Ecológicas Desiguais rompa de certa forma com o paradigma tradicional de desenvolvimento e se proponha a trazer elementos da Economia Ecológica, ela ainda se restringe a uma análise no nível nacional, o que se mostra insuficiente para o debate proposto. Ao mesmo tempo, o modelo das RGPs permite estudos em outras escalas de análise, mas ainda apresenta uma perspectiva europeia de desenvolvimento.
} 
experiências exitosas de construção de alternativas em âmbito local e regional, e criar uma agenda de transição ao "pós-extrativismo".

Em termos da construção de um cenário de desejabilidade, o pós-desenvolvimento uniria uma série de correntes do pensamento decolonial, de forma a desconstruir arcabouços existentes de poder, mito e imaginário que estruturariam o atual modelo de desenvolvimento. Assim, ele se tornou um ponto de encontro para distintos debates que buscariam construir outra relação entre sociedade, natureza e economia, tais como: bem viver, bem comum, direitos da natureza, ecofeminismo, justiça ambiental (SVAMPA, 2013b; 2018) e soberania popular (ALVES et al., 2020).

Elementos como esses seriam fundamentais para superar construções ideacionais como "vocação mineral", "rigidez locacional" e "essencialidade da mineração", entre outros. Portanto, eles permitiriam a elaboração de um novo imaginário em torno da vida, e romperiam com a ideia de priorização dos projetos extrativos em contraposição aos modos de viver existentes.

Um segundo desafio relevante nesse processo diria respeito à identificação de experiências alternativas exitosas. A história latino-americana possui um grande acúmulo de propostas nesse campo, como economia solidária, agricultura familiar, agroecologia, turismo de base comunitária entre outros (SVAMPA, 2013a; ALVES et al., 2020). No processo de valorização dessas iniciativas e de sua consolidação como alternativas aos "projetos de desenvolvimento", muitas passaram a se reconhecer como "territórios livres de mineração" (CASTRO, G. F. et al., 2020), gerando um novo significado político para essas formas organizativas.

Por fim, o terceiro desafio consistiria na construção de um repertório de políticas públicas que compusessem uma agenda de transição para uma nova perspectiva sobre a conexão entre questões sociais e ambientais (SVAMPA, 2013b). No caso específico das políticas públicas, Acosta e Brand (2018) explicitam a necessidade de repensar o papel do Estado. Os autores alertam para a necessidade de se "democratizar a democracia", por meio da intervenção direta da sociedade organizada. Dentro dessa proposta, considera-se que o Estado pode contribuir, desde que seja controlado pela comunidade, e não um Estado que sirva como instrumento de dominação.

$\mathrm{Na}$ construção de uma transição para o pós-extrativismo, Gudynas (2012b) argumenta pela necessidade de se romper com o extrativismo depredador e criar uma transição para um extrativismo sensato, a fim de se atingir o extrativismo indispensável. Para tanto, o autor propõe a promoção do zoneamento territorial de acordo com critérios sociais, ambientais e econômicos; o reconhecimento dos direitos das comunidades tradicionais; a garantia da participação efetiva da sociedade; a internalização das externalidades ambientais e sociais; a revisão de subsídios, entre outros.

Indo por um caminho convergente, o debate sobre soberania popular na mineração propõe estratégias e políticas de aprofundamento da participação popular, tanto em áreas onde não há mineração quanto naquelas onde já ocorrem atividades extrativas. No primeiro caso, defende-se o direito de "dizer não", bem como a primazia da participação direta no licenciamento de projetos por meio de protocolos de consulta desenhados pelas próprias comunidades.

Em áreas onde já há a presença de projetos extrativos, argumenta-se que a população deva poder decidir sobre a escala, o ritmo, as tecnologias e os limites à extração. Também são propostas: a possibilidade de transferência de ativos para trabalhadores; o apoio à mineração de base comunitária; a correção das injustiças tributárias e o controle social do uso dos royalties minerais, bem como o estímulo à migração de trabalhadores para outras atividades e à redução da dependência econômica da extração mineral (PROJETO BRASIL POPULAR, 2016; ALVES et al., 2020). 


\section{Considerações finais}

O presente trabalho foi iniciado com uma breve descrição das principais escolas de pensamento que buscaram discutir a relação entre atividades extrativas e desenvolvimento econômico. Tomando como ponto de partida a leitura normativa do pensamento liberal, buscou-se mostrar como diferentes perspectivas teóricas (Estruturalismo, Teoria da Dependência, Trocas Ecológicas Desiguais, Maldição dos Recursos Naturais, Redes Globais de Produção) foram elaboradas de forma a apresentar, com variados graus de radicalidade, os riscos e as limitações associados à adoção do extrativismo como estratégia de crescimento econômico.

Posteriormente, foi identificado como, apesar dos alertas teóricos, a junção do fortalecimento do discurso neoliberal, do processo de globalização e da emergência econômica asiática levou a uma supervalorização dos recursos minerais e, consequentemente, a uma recondução dos setores extrativistas para o centro das estratégias de desenvolvimento econômico na América Latina. Como resultado, intensificaram-se os impactos ambientais e aprofundaram-se os conflitos territoriais. Em resposta a esse processo, novas perspectivas teóricas foram elaboradas, inclusive questionando a própria noção de desenvolvimento.

Assim, ao longo do texto, buscou-se descrever o processo de renovação do debate latinoamericano no que diz respeito à economia política e às políticas públicas voltadas para as economias extrativas. Esse exercício permitiu identificar que, embora o pensamento crítico elaborado no século XX tenha sido fundamental para apresentar os problemas e as contradições do ideário liberal, em um momento posterior ele passou a apresentar limitações, uma vez que algumas de suas premissas e escalas de análise se mostraram insuficientes para lidar com o aumento da complexidade do mundo dentro do contexto neoliberal, da dominação ideológica do desenvolvimento, da globalização e da expansão crescente dos projetos extrativos sobre territórios até então não incorporados à dinâmica do capitalismo global.

Dessa forma, notou-se que esse "novo ciclo" do extrativismo na América Latina gerou uma renovação dos debates, das construções teóricas e das estratégias de ação. Apesar disso, entendese que as análises críticas construídas ao longo do século XX para debater a relação entre extrativismo e desenvolvimento econômico ainda acumulam importante aprendizado e importante capacidade explicativa.

Portanto, identifica-se como desafio e oportunidade de pesquisas futuras a construção de estruturas analíticas que permitam criar diálogos entre as distintas propostas críticas que envolvem desde modelos alternativos de desenvolvimento até alternativas ao desenvolvimento. Assim, esperase fortalecer a resistência contra a expropriação dos diferentes territórios sob ameaça da expansão das atividades extrativistas, como também garantir a qualidade de vida das comunidades que aí vivem. 


\section{Referências}

ACOSTA, A. (2011) Extractivismo y neoextractivismo: dos caras de la misma maldición. In: DESARROLLO, G. P. D. T. S. A. A. (Ed.). Más alla del desarrollo. Quito: AbyaYala, Fundación Rosa Luxemburg. p. 83-118.

ACOSTA, A.; BRAND, U. (2018). Pós-extrativismo e decrescimento: saídas do labirinto capitalista. São Paulo: Elefante. 224 p.

ALBAVERA, F. S. (2004) El desarrollo productivo basado en la explotación de los recursos naturales. Santiago de Chile: CEPAL. 79 p.

ALTVATER, E. (1993) Ilhas de Sintropia e Exportação de Entropia-Custos Globais do Fordismo Fossilístico. Cadernos do NAEA, n. 11, p. 3-54.

ALVES, M. S. et al. (2020) Comunidades atingidas e territórios afetados pela mineração: realidades e resistências. In: ALVES, M. S.; CARNEIRO, K. G., et al (Ed.). Mineração: realidades e resistências São Paulo: Expressão Popular. p.41-100.

AMAZONAS, M. C. (2001) Valor e meio ambiente: elementos para uma abordagem evolucionista. (Ph.D.). Instituto de Economia, Universidade Estadual de Campinas, Campinas.

(2009) Valor ambiental em uma perspectiva heterodoxa institucional-ecológica. Economia e Sociedade, v. 18, n. 1, p. 183-212.

ARANIBAR, A. M.; CHAPARRO AVILA, E.; SALGADO, R. (2011). La industria extractiva en América Latina y el Caribe y su relación con las minorías étnicas. Santiago: Comisión Económica para América Latina. $63 \mathrm{p}$.

AUTY, R. M. (1993) Sustainable development in mineral economies: the resource curse thesis. London: Routledge. 284 p.

BAINTON, N.; OWEN, J. R.; KEMP, D. (2020) Invisibility and the extractive-pandemic nexus. The Extractive Industries and Society, v. 7, n. 3, p. 841-843.

BARTON, J. R. (2006) Eco-dependency in Latin America. Singapore Journal of Tropical Geography, v. 27, n. 2, p. 134-149.

BAZILIAN, M. D. (2018) The mineral foundation of the energy transition. The Extractive Industries and Society, v. 5, n. 1, p. 93-97.

BEBBINGTON, A. (2010) Extractive industries and stunted states: conflict, responsibility and institutional change in the Andes. In: RAMAN, K. R. e LIPSCHUTZ, R. D. (Ed.). Corporate social responsibility: discourses, practices and perspectives. Hampshire: Palgrave MacMillan. p. 97-115.

BNAMERICAS. (2020) Mining in Latin America: An essential activity?. Disponível em: <https://www.bnamericas.com/en/features/mining-in-latin-america-an-essential-activity Acessado em: 30 Abr 2021.

BRIDGE, G. (2008) Global production networks and the extractive sector: governing resource-based development. Journal of Economic Geography, v. 8, n. 3, p. 389-419.

BUNKER, S. G. (1984) Modes of extraction, unequal exchange, and the progressive underdevelopment of an extreme periphery: the Brazilian Amazon, 1600-1980. American Journal of Sociology, v. 89, n. 5, p. 1017-1064.

. (1985) Underdeveloping the Amazon: extraction, unequal exchange, and the failure of the modern state. Chicago: University of Chicago Press. 296 p.

BURCHARDT, H.-J. (2016) El neo-extractivismo en el siglo XXI. Qué podemos aprender del ciclo de desarrollo más reciente en américa Latina. In: BURCHARDT, H.-J.; DOMÍNGUEZ, R., et al (Ed.). Nada dura para siempre: neo-extractivismo tras el boom de las materias primas. Toledo; Kassel: Universidad Andina Simón Bolívar; International Center for Development and Decent Work. p.55-87.

CARDOSO, F. H.; FALETTO, E. (1975) Dependência e desenvolvimento na América Latina: ensaio de interpretação sociológica. Rio de Janeiro: Zahar Editores. 236 p.

CASTRO, F. F. et al. (2020) The impacts of Covid-19 on the major mining municipalities in Brazil. Revista do Serviço Público, v. 71, n. Special, p. 42-69.

CASTRO, G. F. et al. (2020) Luta e resistência em busca de um território livre de mineração: Relato sobre o enfrentamento à mineração de bauxita na Serra do Brigadeiro (MG). In: ALVES, M. S.; 
CARNEIRO, K. G., et al (Ed.). Mineração: realidades e resistências São Paulo: Expressão Popular. p.321350.

CAVALCANTI, C. (2010) Concepções da economia ecológica: suas relações com a economia dominante e a economia ambiental. Estudos avançados, v. 24, n. 68, p. 53-67.

CHAPARRO, E. (2002) Actualización de la compilación de leyes mineras de catorce países de América Latina y el Caribe. Santiago de Chile: CEPAL. 120 p.

$\mathrm{CHURCH}$, C.; CRAWFORD, A. (2020) Minerals and the metals for the energy transition: exploring the conflict implications for mineral-rich, fragile states. In: HAFNER, M. e TAGLIAPIETRA, S. (Ed.). The Geopolitics of the Global Energy Transition. Cham: Springer International Publishing. p.279-304.

COE, N. M.; DICKEN, P.; HESS, M. (2008) Global production networks: realizing the potential. Journal of economic geography, v. 8, n. 3, p. 271-295.

COELHO, T. P. (2016) Noventa por cento de ferro nas calçadas: mineração e (sub)desenvolvimentos em municípios minerados pela Vale S.A. (Ph.D.). Programa de Pós-graduação em Ciências Sociais, Universidade do Estado do Rio de Janeiro., Rio de Janeiro.

COONEY, S. et al. (2008) Minerals price increases and volatility: causes and consequences. Washington: Congressional Research Service. 49 p.

DALY, H. E.; FARLEY, J. (2004) Ecological Economics: principles and applications. Washington, DC: Island Press. 488 p.

DAVIS, G. A.; TILTON, J. E. (2005) The resource curse. Natural Resources Forum, v. 29, n. 3, p. 233-242. DEVARAJAN, S.; FISHER, A. C. (1981) Hotelling's" economics of exhaustible resources": Fifty years later. Journal of Economic Literature, v. 19, n. 1, p. 65-73.

DOS SANTOS, T. (1970) The structure of dependence. The American Economic Review, v. 60, n. 2, p. 231-236.

EDWARDS, D. P. et al. (2014) Mining and the African environment. Conservation Letters, v. 7, n. 3, p. 302-311.

EJOLT. (2016) Environmental Justice Atlas Environmental Justice Organisations, Liabilities and Trade. Disponível em: < https://ejatlas.org/ > . Acessado em: 30 Abr 2021.

ESCOBAR, A. (1995) Encountering development the making and unmaking of the Third World. Princeton, NJ: Princeton University Press. 290 p.

FERREIRA, L. T. (2020) "Gato e sapato": a solução negociada e a pilhagem da bacia do rio Doce. Revista Eletrônica Direito e Sociedade-REDES, v. 8, n. 2, p. 163-180.

FURTADO, C. (1965) Development and stagnation in Latin America: a structuralist approach. Studies in Comparative International Development, v. 1, n. 11, p. 159-175.

GELB, A. H. (1988) Oil windfalls: Blessing or curse? New York: Oxford University Press. 368 p.

GEORGESCU-ROEGEN, N. (1971) The entropy law and the economic process. Cambridge, MA: Harvard University Press. $450 \mathrm{p}$.

GONÇALVES, R. J. A. F.; MILANEZ, B. (2020) The territorialization of the niobium global extractive network in Goiás, Brazil. Ateliê Geográfico, v. 14, n. 2, p. 142-162.

GONZÁLEZ, N. (2019) La conflictividad vinculada a los recursos naturales en América Latina: tendencias y mecanismos institucionales de respuesta. In: SÁNCHEZ, R. J. (Ed.). La bonanza de los recursos naturales para el desarrollo: dilemas de gobernanza. Santiago: Comisión Económica para América Latina. p. 359-372.

GORDON, T.; WEBBER, J. R. (2016) Blood of extraction: Canadian imperialism in Latin America. Halifax; Winnipeg: Fernwood Publishing. 400 p.

GRAULAU, J. (2008) 'Is mining good for development?' the intellectual history of an unsettled question. Progress in Development Studies, v. 8, n. 2, p. 129-162.

GUDYNAS, E. (2012a) Estado compensador y nuevos extractivismos. Nueva Sociedad, v. 237, p. 128146.

(2012b) Hay alternativas al extractivismo: Transiciones para salir del viejo desarrollo. Jesús María: Centro Peruano de Estudios Sociales; Red Peruana por una Globalización con Equidad. 44 p. . (2012c) O novo extrativismo progressista na América do Sul: teses sobre um velho problema sob novas expressões. In: LÉNA, P. e PINHEIRO DO NASCIMENTO, E. (Ed.). Enfrentando os limites do 
crescimento: sustentabilidade, decrescimento e prosperidade. Rio de Janeiro: Garamond; IRD. p. 303318.

(2015) Extractivismos. Ecología, economía y política de un modo de entender el desarrollo y la Naturaleza. Cochabamba: Centro de Documentación e Información Bolívia. 456 p.

(2017) Posdesarrollo como herramienta para el análisis crítico del desarrollo. Estudios Críticos sobre el Desarrollo, v. 7, n. 12, p. 193-210.

HASLAM, P. A.; HEIDRICH, P. (2016a) From neoliberalism to resource nationalism: states, firms and development. In: HASLAM, P. A. e HEIDRICH, P. (Ed.). The political economy of natural resources and development: from neoliberalism to resource nationalism. Abingdon; New York: Routledge. p. 1-32.

(2016b) Towards a theory of resource nationalisms. In: HASLAM, P. A. e HEIDRICH, P. (Ed.). The political economy of natural resources and development: from neoliberalism to resource nationalism. Abingdon; New York: Routledge. p. 223-235.

HENDERSON, J. et al. (2002) Global production networks and the analysis of economic development. Review of international political economy, v. 9, n. 3, p. 436-464.

HORNBORG, A. (1998) Towards an ecological theory of unequal exchange: articulating world system theory and ecological economics. Ecological economics, v. 25, n. 1, p. 127-136.

HOTELLING, H. (1931) The economics of exhaustible resources. Journal of political Economy, v. 39, n. 2, p. $137-175$.

ITC. (2021) Trade Map. International Trade Centre. Disponível em: < https://www.trademap.org >. Acessado em: 29 Abr 2021.

KLARE, M. (2012) The race for what's left: the global scramble for the world's last resources. Picador. $320 \mathrm{p}$.

LEITE, C.; WEIDMANN, J. (1999) Does mother nature corrupt? Natural resources, corruption, and economic growth. Washington: International Monetary Fund. 33 p.

MARTINEZ-ALIER, J. (2002) The environmentalism of the poor: a study of ecological conflicts and valuation. Cheltenham: Edward Elgar Pub. 208 p.

MATTEI, L.; SANTOS JÚNIOR, J. A. (2009) Industrialização e substituição de importações no Brasil e na Argentina: uma análise histórica comparada. Revista de Economia, v. 35, n. 1, p. 93-115.

MATTLI, W.; WOODS, N. (2009) In whose benefit? Explaining regulatory change in global politics. In: MATTLI, W. e WOODS, N. (Ed.). The politics of global regulation. Princeton; Oxford: Princeton University Press. p. 1-43.

MEHLUM, H.; MOENE, K.; TORVIK, R. (2006) Institutions and the resource curse. The Economic Journal, v. 116, n. 508, p. 1-20.

MIGUEL, C.; PEREIRA, M. (2019) Pasivos ambientales mineros: retos para la sostenibilidad. In: SÁNCHEZ, R. J. (Ed.). La bonanza de los recursos naturales para el desarrollo: dilemas de gobernanza. Santiago: Comisión Económica para América Latina. p. 373-394.

MILANEZ, B. Boom ou bolha? (2017) A influência do mercado financeiro sobre o preço do minério de ferro no período 2000-2016. v.1, n. S2. Versos - Textos para Discussão PoEMAS, v. 1, n. S2, p. 1-18.

MILANEZ, B.; ALI, S. H.; PUPPIM DE OLIVEIRA, J. A. (2021) Mapping industrial disaster recovery: Lessons from mining dam failures in Brazil. The Extractive Industries and Society, v. 8, n. 2, p. 100900. MILANEZ, B.; COELHO, T. P.; WANDERLEY, L. J. M. (2017) O projeto mineral no Governo Temer: menos Estado, mais mercado. Versos - Textos para Discussão PoEMAS, v. 1, n. 2, p. 1-15.

MILANEZ, B.; SANTOS, R. S. P. (2018) Extraction minière, stratégie d'entreprise et flexibilisation de la réglementation environnementale au Brésil: le cas du projet Minas-Rio. Brésil(s). Sciences humaines et sociales, v. 13.

. (2019) Embedded corporate strategies and power: The case of Vale SA in Itabira, Brazil. The Extractive Industries and Society, v. 6, n. 3, p. 889-896.

MONTEIRO, M. A. (2005) Meio século de mineração industrial na Amazônia e suas implicações para o desenvolvimento regional. Estudos avançados, v. 19, n. 53, p. 187-207.

MONTEIRO, M. A.; COELHO, M. C. N. (2008) Mineração e entropia: notas sobre interação com processos de desenvolvimento. Novos Cadernos NAEA v. 10, n. 1, p. 23-44. 
NADER, L. (1990) Harmony ideology: Justice and control in a Zapotec mountain village. Stanford University Press. 343 p.

OCMAL (2021). Miembros OCMAL. Observatorio de Conflictos Mineros de América Latina. Disponível em: < https://www.ocmal.org/miembros-ocmal/ >. Acessado em: 03 Mai 2021.

OEA. (2016) Declaração Americana sobre os Direitos dos Povos Indígenas: AG/RES.2888 (XLVI-O/16): (Aprovada na terceira sessão plenária, realizada em 15 de junho de 2016). Santo Domingo, República Dominicana: Organização dos Estados Americanos.

OIT. (2011) Convenção n 169 sobre povos indígenas e tribais e Resolução referente à ação da OIT. Brasília: Organização International do Trabalho, Escritório no Brasil.

ONU. (2008) Declaração das Nações Unidas sobre os Direitos dos Povos Indígenas. Rio de Janeiro: Oganização das Nações Unidas.

PEARCE, D. (2002) An intellectual history of environmental economics. Annual review of energy and the environment, v. 27, n. 1, p. 57-81.

PETERS, S. (2016) Fin del ciclo: el neo-extractivismo en suramérica frente a la caída de los precios de las materias primas. Un análisis desde una perspectiva de la teoría rentista. In: BURCHARDT, H.-J.; DOMÍNGUEZ, R., et al (Ed.). Nada dura para siempre: neo-extractivismo tras el boom de las materias primas. Toledo; Kassel: Universidad Andina Simón Bolívar; International Center for Development and Decent Work. p. 21-53.

POWER, T. M. (2002) Digging to development? A historical look at mining and economic development. Boston: Oxfam America. $44 \mathrm{p}$.

PREBISH, R. (1949) El desarrollo económico de la América Latina y algunos de sus principales problemas. Santiago: Comissão Econômica para a América Latina e o Caribe, 63 p.

PROJETO BRASIL POPULAR. (2016) Mineração. Disponível em: < https://sites.google.com/view/projetobrasilpopular/eixo-02-economia-desenvolvimento-edistribui\%C3\%A7\%C3\%A3o-de-renda/minera\%C3\%A7\%C3\%A30 >. Acessado em: 09 Mai 2021.

RICE, J. (2007) Ecological unequal exchange: Consumption, equity, and unsustainable structural relationships within the global economy. International Journal of Comparative Sociology, v. 48, n. 1, p. 43-72.

ROBERTS, J. T.; PARKS, B. C. (2009) Ecologically unequal exchange, ecological debt, and climate justice: The history and implications of three related ideas for a new social movement. International Journal of Comparative Sociology, v. 50, n. 3-4, p. 385-409.

ROSS, M. L. (1999) The political economy of the resource curse. World Politics, v. 51, n. 2, p. 297-322. ROSTOW, W. W. (1960) The stages of economic growth: A non-communist manifesto. Cambridge, MA: Cambridge University Press. 324 p.

RUBBERS, B. (2020) Mining boom, labour market segmentation and social inequality in the Congolese Copperbelt. Development and Change, v. 51, n. 6, p. 1555-1578.

SACHS, J. D.; WARNER, A. M. (1995) Natural resource abundance and economic growth. Cambridge, MA: National Bureau of Economic Research. 47 p.

(2001) The curse of natural resources. European economic review, v. 45, n. 4-6, p. 827-838.

SAES, B. M. (2017) Comércio ecologicamente desigual no século XXI: evidências a partir da inserção brasileira no mercado internacional de minério de ferro. (Ph.D.). Instituto de Economia, Universidade Estadual de Campinas, Campinas.

. (2018) El boom de las commodities ante la fragmentación internacional de la producción: una perspectiva ambiental desde el Sur global. Puentes: análisis e información sobre comercio y desarrollo sostenible, v. 19, n. 6, p. 8-11.

SANTOS, R. S. P.; MILANEZ, B. (2015) The Global Production Network for iron ore: materiality, corporate strategies, and social contestation in Brazil. The Extractive Industries and Society, v. 2, n. 4, p. $756-765$.

(2017) The construction of the disaster and the "privatization" of mining regulation: reflections on the tragedy of the Rio Doce Basin, Brazil. Vibrant: Virtual Brazilian Anthropology, v. 14, n. 2, p. e142127. 
SCHAPER, M.; VÉRÈZ, V. O. (2001) Evolución del comercio y de las inversiones extranjeras en industrias ambientalmente sensibles: Comunidad Andina, Mercosur y Chile (1990-1999). Santiago de Chile. 73 p. SIKKINK, K. (1991) Ideas and institutions: developmentalism in Brazil and Argentina. Ithaca: Cornell University Press. 288 p.

SLIPAK, A. M. (2014) América Latina y China:i cooperación sur-sur o Consenso de Beijing? Nueva Sociedad, n. 250, p. 102-113.

SOLOW, R. M. (1974) The economics of resources or the resources of economics. The American Economic Review, v. 64, n. 2, p. 1-14.

SVAMPA, M. N. (2013a.) Consenso de los commodities y lenguajes de valoración en América Latina. Nueva Sociedad, n. 244, p. 30-46

(2013b) Resource extractivism and alternatives: Latin American perspectives on development. In: LANG, M.; FERNANDO, L., et al (Ed.). Beyond development: alternative visions from Latin America. Quito; Amsterdam: Transnational Institute; Rosa Luxemburg Foundation. p.117-143. (2018) Latin American development: perspectives and debates. In: FALLETI, T. G. e PARRADO,

E. A. (Ed.). Latin America since the left turn. Philadelphia: University of Pennsylvania Press. p.13-32.

SVAMPA, M. N.; SLIPAK, A. M. (2015) China en América Latina: del consenso de los commodities al consenso de Beijing. Revista Ensambles, v. 2, n. 3, p. 34-63.

THE WORLD BANK. (2021) "Pink sheet" data: annual prices. Commodity Markets. Disponível em: < https://www.worldbank.org/en/research/commodity-markets >. Acessado em: 25 Fev 2021.

VIALE, C.; CRUZADO, E. (2012) La distribución de la renta de las industrias extractivas a los gobiernos subnacionales en América Latina. Lima: Revenue Watch Institute. 56 p.

VIEGAS, R. N.; GIFFONI PINTO, R.; GARZON, L. F. N. (2014) Negociação e acordo ambiental: o termo de ajustamento de conduta (TAC) como forma de tratamento dos confitos ambientais. Rio de Janeiro: Fundação Heinrich Böll. 309 p.

WALLERSTEIN, I. (1974) The Modern World-System I: capitalist agriculture and the origins of the european world-economy in the sixteenth century. New York: Academic Press. 440 p.

(1980) The Modern World-System II: mercantilism and the consolidation of the European worldeconomy, 1600-1750. New York: Academic Press. 400 p.

(1989) The Modern World System III: the second era of great expansion of the capitalist worldeconomy, 1730s-1840s. New York: Academic Press. 392 p.

WICK, K.; BULTE, E. (2009) The curse of natural resources. Annual Review of Resource Economic, v. 1, n. 1, p. 139-156. 